\title{
Simulation of river water quality from in-situ data and satellite imagery, focus on organic pollutants ${ }^{\dagger}$
}

\author{
Tran Thi Van 1,*, Ha Duong Xuan Bao ${ }^{1}$, Pham Thi Anh My ${ }^{1}$, Tran Lap Phong ${ }^{1}$, Tran Viet Tri ${ }^{1}$ \\ 1 Ho Chi Minh City University of Technology, Vietnam National University Ho Chi Minh City; \\ tranthivankt@hcmut.edu.vn \\ 1 Ho Chi Minh City University of Technology, Vietnam National University Ho Chi Minh City; \\ hdxbao@hcmut.edu.vn \\ 1 Ho Chi Minh City University of Technology, Vietnam National University Ho Chi Minh City; \\ phammy1311@gmail.com \\ 1 Ho Chi Minh City University of Technology, Vietnam National University Ho Chi Minh City; \\ lapphong1993@gmail.com \\ 1 Ho Chi Minh City University of Technology, Vietnam National University Ho Chi Minh City; \\ tritv91103818mo11qlmt@gmail.com \\ * Correspondence: tranthivankt@hcmut.edu.vn ; Tel.: +84-028-091-918-8485 \\ + Presented at the 2nd International Electronic Conference on Water Sciences (ECWS-2) on 16-30 November \\ 2017 \\ Academic Editor: name \\ Received: date; Accepted: date; Published: date
}

\begin{abstract}
Water is an essential ingredient of life. Currently, this natural resource has been under pressure from the socio-economic development. This paper presents the application of remote sensing technology to monitor organic pollutants in water from Hoa An bridge to the confluence of the Saigon and Dong Nai River. The river water indicator was surveyed as Dissolved Oxygen (DO) and was calculated via spectral channels of Landsat 8 at the time of January 21, 2014. Research methods was approached in the direction of: Qualitative simulation from the spectral characteristics, and quantitative simulation based on regression analysis. The results showed that the concentration of the observed indicator $\mathrm{DO}$ had a linear correlation with the ratio based on green band B3 and red band B4 of Landsat 8 image. From the regression, this study established the spatial distribution maps to simulate organic pollutants in rive water of the studied area. The classification system was built according to the standards of QCVN08:2008/BTNMT. The study results shows that the application of remote sensing monitoring river water quality is a good support tool for environmental management purposes, to help policy-makers to see and have better decisions for the local socio-economic development.
\end{abstract}

Keywords: band ratio; organic pollutants; regression analysis; spectral characteristics

\section{Introduction}

Water resource is an essential part of life, determining the success of strategy, project, plan for socio-economic development, assuring the national defense and security. Currently, this precious, important natural resource is scarce and under pressure from economic and social development. Water are used in agricultural and industrial activities, manufacturing, entertainment and environment that need fresh water. Fresh water is a renewable resource; however, the supply of fresh and clean water in the world as well as in Vietnam is gradually decreasing. Water demand has surpassed supply in some parts of the world, while the world's population continues to increase, making water demand rise. Awareness of the importance of water protection for ecosystem needs 
has only recently been raised. Therefore, it is necessary to quickly have effective monitoring and management measures to protect this natural resource. While traditional environmental monitoring tools still have limitations on spatial information and objectivity.

Remote sensing technology is playing a vital role in recent decades in global climate change and permanent degradation of the aquatic ecosystem because the demand for drinking water is increasing and water is contaminated by the flow. To monitor and manage pollution, remote sensing technology can provide data and processing methods to detect and estimate, forecast the contaminated areas in river basin

This paper presents a study on the spectral properties of remote sensing images, incorporating image modification indices to detect changes in organic properties within river surface water, and to analyze regression correlations to determine the concentration of pollutant spatially distributed across the river

\section{Study Area and Data}

The research area is located at Dong Nai river. This is the second largest river system in the Southern Vietnam, and the third largest in Vietnam. Its vast basin almost entirely lies in our territory, only a small part spreads in another country (Cambodia). Dong Nai river runs along mostly eastern part of Dong Nai Province, where many industrial areas and manufacturing factories are located, with waste drainage lines flowing into this river system. The study area is where the ground observation of Dong Nai Center of Environmental Monitoring and Technique (CEMT) is located, starting from Hoa An bridge; At the same time, to consider the flow of influence, the area is extended to the south extending to the confluence of Saigon - Dong Nai river system (Figure 1).

The research data is the Landsat 8 image captured on January 21, 2014, and was downloaded free from The United States Geological Survey's website (USGS). It includes 11 spectral bands, 8 of which are the reflectance bands with resolution of 30m; 2 of which are thermal infrared bands with resolution of $100 \mathrm{~m}$ and the other is panchromatic band with $15 \mathrm{~m}$ in resolution. Moreover, the ground data collected from the Center were acquired at the same time when the Landsat 8 images captured on that day. These samples were analyzed at the laboratory of the Center [1].

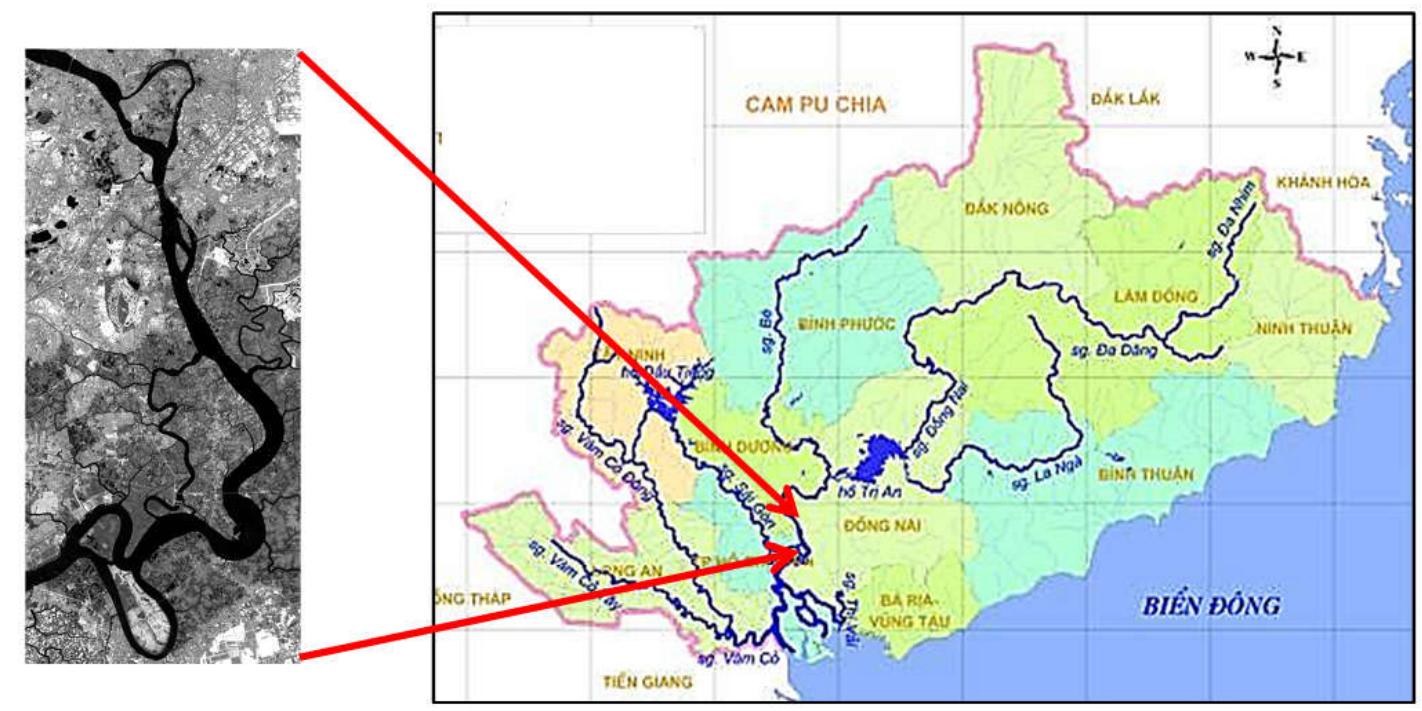

Figure 1. Study area in the Saigon-Dong Nai river system

\section{Methodology}

The fundamental principle of remote sensing is the reflection or emission characteristics of natural objects corresponding to the different spectrums [3]. The result of interpreting layers depends on the understanding on the correlation between reflection spectrum features and nature or state of natural objects. The information on reflection spectrum features of natural objects will allow the selection of optimal bands, consisting most of information on research objects. Meanwhile, this is 
the basis to analyze the research on characteristics of objects, and then classify them. When examining spectrum characteristics, we will get qualitative results. If we need to determine the concentration, we need the quantitative model to simulate. This research approaches to two directions: qualitative and quantitative for organic pollution.

\subsection{Qualitative water quality from satellite image}

The organic contamination level in water is displayed by BOD and DO parameter. Therein, the high level of organic presence leads to the decline of DO level in water due to the oxygen consumption of microorganism to decompose organic matter. The decrease of DO in water will negatively affect aquatic life. DO is the dissolved oxygen in water. Dissolved water will participate in the metabolism process, maintain the energy for process of development and reproduction for microorganism living in water. The lower the DO level is, the more severely contaminated the water will be.

\subsubsection{Creating the Normalized Difference Vegetation Index (NDVI)}

Creating NDVI aims to emphasize on vegetation cover where NDVI value lies from -1 to +1 . NDVI $=+1$ means the presence of high density of vegetation; NDVI $=0$ means the land with no vegetation or scattered ones; NDVI $=-1$ means bare land or water surface. Regarding the observation inside water, the presence of organic matter inside water will be displayed with NDVI value. For the water area with high organic contamination, NDVI value will reach to high or maximum. NDVI is defined as following:

$$
\mathrm{NDVI}=(\mathrm{NIR}-\mathrm{RED}) /(\mathrm{NIR}+\mathrm{RED})
$$

\subsubsection{Creating band from Principal Component Analysis (PCA)}

PCA is method of transforming the pixel values. This transformation will compress the image data by retaining the maximum amount of useful information and removing duplication ones.

\subsubsection{Color combination}

Incorporating the component video channels through the Red-Green-Blue color combination will help identify the characteristics of the object's distribution. In addition to the two NDVI and PC1 image bands that have been developed from the image-transforming technique, the Blue Spectral band is the region that exhibits the strongest reflectivity of the pure water (equivalent to band 2 of the Landsat 8 image), which helps to separate water from vegetation and soil better:

Red: NDVI - Green: Band 2 - Blue: PC1

\subsection{Quantitative water quality from image}

To establish the spatial distribution map of surface water's polluted components from satellite images, we must first create the water quality estimation model based on the reflection leaving from water surface. When creating the model, we must demonstrate correctly and objectively without imposing human's awareness of organic relationship between water quality variables and reflection from water surface. To achieve these goals, we must follow 2 requirements: (1) Find the objective existence relationship between water quality variables and reflection leaving from water surface; (2) Select appropriate model to create water quality model.

The utilization model is a regression analysis problem, an estimation or forecast process based on the given values of other variables. The result of regression analysis is to find out the form of regression model; this is an experimental issue. Form of the regression analysis will decide the research result [2]). The correlation relationship among phenomena is demonstrated by linear equation. In many analysis cases, the relationship is shown to be non-linear; however, some people suppose that if the numerical error is not great enough, the linear equation can be used to describe 
an approximation and the calculation process is much simpler. Sometimes, when this relationship is not clear, it is presumed as linear relationship [5]. Therefore, the author limited the research into linear regression analysis to depict the relationship between independent and dependent variables.

When examining the correlation between land surface measurements with image bands and surveyed ratio of DO (Table 1), the suitable linear regression model chosen as independent variable was ratio $\mathrm{B} 4 / \mathrm{B} 3$ and dependent variable was $\mathrm{DO}$ with the highest correlation ratio $\mathrm{R}=0.914$. The determined regression function is: $\mathrm{Y}=-34.387 \mathrm{X}+36.009$, with $\mathrm{R} 2=0.83$ (Figure 2). This result function was used to simulate the distribution of $\mathrm{DO}$ on the whole surveyed river.

Table 1. Correlation coefficient of surveyed ratios

\begin{tabular}{ccccccccc}
\hline Surveyed ratio & B2 & B3 & B4 & B5 & B3/B2 & B4/B2 & B5/B2 & B2/B3 \\
\hline DO $(\mathrm{mg} / \mathrm{L})$ & -0.126 & 0.073 & -0.846 & -0.300 & 0.247 & -0.885 & -0.291 & -0.247 \\
\hline Surveyed ratio & B4/B3 & B5/B3 & B2/B4 & B5/B4 & B2/B5 & B3/B5 & B4/B5 & \\
\hline DO $(\mathrm{mg} / \mathrm{L})$ & $-0.914^{*}$ & -0.291 & 0.888 & -0.212 & 0.347 & 0.347 & 0.197 & \\
\hline
\end{tabular}

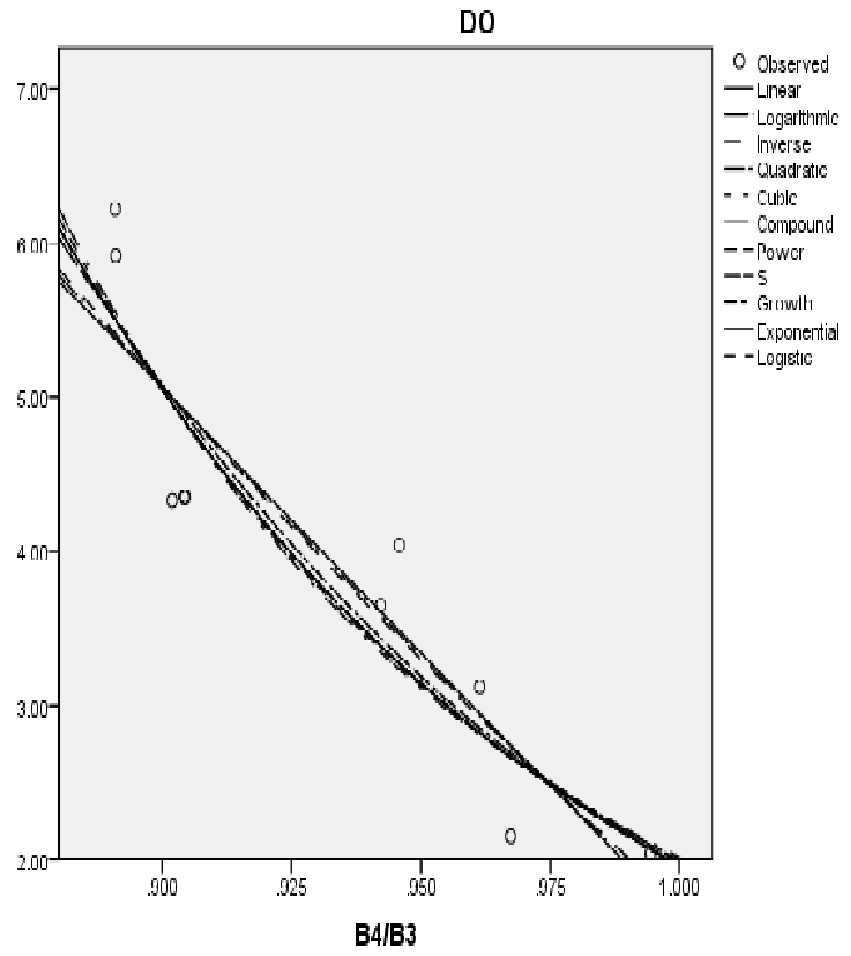

Figure 2. Graph illustrates correlation of DO concentration and B4/B3 ratio

\subsection{Classification of DO content to assess quality}

Quantitative results are expressed in the form of zoning according to the threshold value system of Vietnam standard QCVN08: 2015 / BTNMT [4]. Accordingly, the value thresholds specified for surface water use include columns A1, A2, B1 and B2. Research uses this rating scale to evaluate the dissolved oxygen content of water (Table 2):

- Column A1: DO threshold value best used for domestic water supply

- Column A2: DO threshold value used for domestic water supply but appropriate treatment technology must be applied; or used for the conservation of aquatic plants and animals

- Column B1: DO thresholds used for irrigation or other uses with similar water quality requirements

- Column B2: DO threshold value for navigation and other purposes with low quality water requirements

- Column C: is prescribed for value beyond the standard table (by the author convention) 
Table 2. Threshold value of DO content according to QCVN

\begin{tabular}{llllll}
\hline Classified by standards & A1 & A2 & B1 & B2 & C \\
\hline $\mathrm{DO}(\mathrm{mg} / \mathrm{l})$ & $\geq 6$ & $\geq 5$ & $\geq 4$ & $\geq 2$ & $<2$ \\
\hline
\end{tabular}

(Source: QCVN08:2015/BTNMT)

\section{Results and Dicussion}

(a)

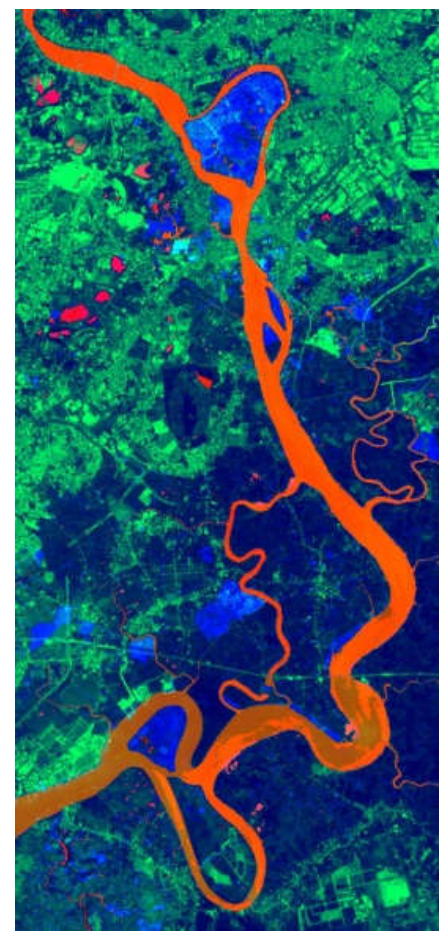

(b)

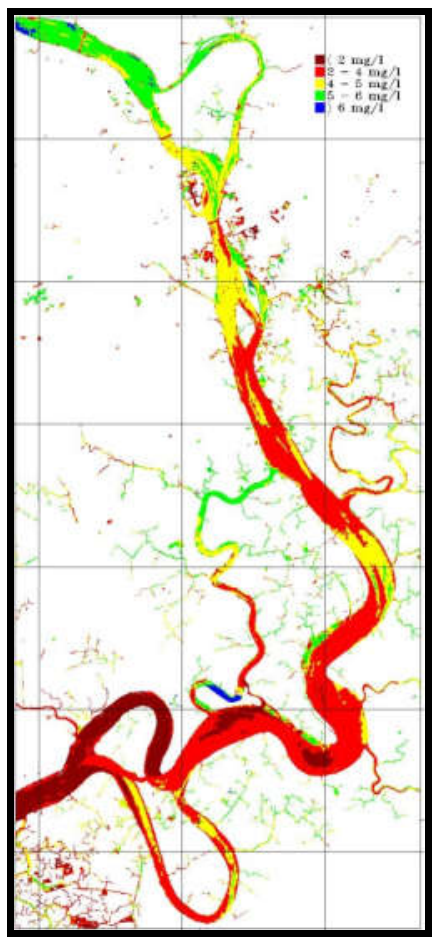

Figure 3. (a) Color combining image: Red: NDVI; Green: Band 2; Blue: PC Band; (b) A simulation of DO content exists in the surface waters of the river

\subsection{Qualitative results on $D O$ distribution}

Color combinations (Figure 3a) show that the river section is clearly separated from the land and vegetation on the shoreline. The red color is assigned to the NDVI channel. The bright red color indicates that the vegetation content in the river is less, the dark red color reflects the concentration of the large amount of vegetation suspended in the river. This gives us the conjecture that the presence of organic matter in water will be related to the change in DO content. When the amount of organic water in the water is high, the DO content is strongly reduced and vice versa. In terms of distribution, it can be surmised that:

- From the Hoa An Bridge to the confluence of the Buong River and Dong Nai River, the organic content of the water is low, there may be no signs of pollution or only slight pollution

- The section from the confluence of the Buong River and the Dong Nai River to the confluences of the Saigon River, Dong Nai River and the upstream of the Saigon River show more organic pollution

\subsection{Quantitative results on $D O$ distribution}

There is a good match between the qualitative and quantitative results shown on the two maps (Figure 3b). Evaluation of content distribution is presented below. 
Statistical results showed that the DO content in the study river was lower than $6 \mathrm{mg} / \mathrm{l}$. The distribution of DO content is uneven. DO in the northern region is of better quality, most concentrations are $\geq 4 \mathrm{mg} / \mathrm{l}$, the southern area is only greater than $2 \mathrm{mg} / \mathrm{l}$. This explains the fact that in the north, especially in areas near the Bien Hoa water supply and $\mathrm{Cu}$ Lao Pho area, suitable conditions for aquatic organisms to thrive. It has many fishing villages and fishing camps sprung up, while in the southern region there is almost no production areas in this form. This reflects that the DO content in this area is higher than in other areas.

- Dong Nai River from Hoa An bridge to Dong Nai bridge

Areas with DO concentrations $>5 \mathrm{mg} / 1$ are concentrated in locations such as Bien Hoa Water Supply Plant and some scattered areas along Hoa An Bridge, Rach Cat Bridge and Ca Be Village. In these places, the DO content meets A2 standards, suitable for the domestic water supply through appropriate treatment and conservation of aquatic animals. In the areas of Tan Mai Paper Company, confluence in Suoi Linh Stream, Dong An An Hao, Dong Nai Bridge, the DO content meets only B1 standard $(\mathrm{DO} \geq 4 \mathrm{mg} / \mathrm{l})$. This area receives wastewater from Bien Hoa 1 Ind ustrial Zones, Bien Hoa 2 Industrial Park, Loteco Industrial Park and domestic waste water from Bien Hoa City through streams and canals. As a result, the quality of DO is lower than that of river water at the beginning.

- Dong Nai River from the confluence of the Buong River and Dong Nai River to the confluence of Saigon River and Dong Nai River

In the south of the river, the quality of the DO is rather low, almost satisfying the B2 standard with a DO content of only $\geq 2 \mathrm{mg} / \mathrm{l}$, reaching the point of use only for navigational purposes, and other purposes with low water quality requirements. In the confluence of Tac River - Dong Nai River, the DO content is quite low $\leq 2 \mathrm{mg} / \mathrm{l}$. Similarly, in the river section of Long Tan commune, Nhon Trach district shows signs of organic pollution with very low DO content $\leq 2 \mathrm{mg} 1$. However, this level of pollution has not spread to all areas of the river. This area is directly affected by the activities of Nhon Trach Industrial Park and activities of people in Long Tan commune.

\subsection{Evaluate simulation results}

The accuracy evaluation is calculated from the average bias among estimated values from each method with actual measured value and absolute error E (\%) by the formula as following:

$$
\begin{aligned}
& \text { bias }=\frac{1}{N} \sum_{i=1}^{N}\left(T_{S i}^{\text {calculate }}-T_{S i}^{\text {measure }}\right) \\
& E(\%)=\frac{\left|T_{S i}^{\text {calculate }}-T_{S i}^{\text {measure }}\right|}{T_{S i}^{\text {measure }}} * 100
\end{aligned}
$$

where $\mathrm{N}$ is the number of samples collected to calculate error, $\mathrm{T} \neg$ calculate và Tmeasure are values calculated from satellite images and actual ground data.

Table 3. Results of DO content error in locations

\begin{tabular}{lllll}
\hline Location & DO Measured & DO Calculated & Bias & E(\%) \\
\hline SW-DN-09 & 4.2 & 4.5 & 0.3 & 7.1 \\
SW-DN-11 & 3.0 & 3.2 & 0.2 & 6.7 \\
SW-DN-16 & 3.4 & 3.6 & 0.2 & 5.9 \\
Average Bias & & & 0.2 & 6.6 \\
\hline
\end{tabular}


On the error table, the results from the satellite images are higher than the ground measurements and the deviation between them is negligible, with a mean error of 0.2 and an absolute error of $6.6 \%$. This is acceptable with medium resolution images such as Landsat. However, in order to correct this error, it is necessary to increase the number of observations to increase the data set used to construct regression correlations. In fact, the increase in the number of observations on the ground is difficult to accomplish due to expensive funding as well as manpower. Thus, with the accuracy of the results of the study, remote sensing technology still has the potential and good support for environmental management in a large area.

\section{Conclusion}

Remote sensing is a feasible method for monitoring surface water organic pollution from the spectral characteristics associated with regression analysis. Research methods allow to simulate distribution of pollutant content in rivers. Research shows that qualitative and quantitative methods of simulation produce similar results. The NDVI indicator indicates the presence of organic matter suspended in water. Regression analysis shows the true content of organic pollutants. The regression model indicates that the R-squared coefficient above 0.8 is good. This will improve better if the ground measurements are increased densely. However, the results of this study have demonstrated the high feasibility and application of remote sensing in monitoring and management of surface water environment when there is a combination of satellite imagery and terrain measurements to supplement for each other. At the same time, research results show that remote sensing technology used in river water quality monitoring is a good tool for environmental management, helping policymakers see and make decisions better in the socio-economic development of the locality.

\section{References}

1. Center of Environmental Monitoring and Technology of Dong Nai Province (CEMT). Monitoring measurements of Dong Nai River's water quality, 2014

2. Hoang Trong and Chu Nguyen Mong Ngoc. Analyzing research data with SPSS, Hong Duc Publishing Company, 2008

3. Le Van Trung. Remote sensing. Ho Chi Minh City National University Publishing Company, 2015

4. Ministry of Natural Resources and Environmen. QCVN08:2015/BTNMT: National technical standards on surface water, published on December 21, 2015.

5. Nguyen Tran Que and Vu Manh Ha. Economic statistics, Hanoi National University Publishing Company, 2008

(C) 2017 by the authors. Submitted for possible open access publication under the terms and conditions of the Creative Commons Attribution (CC BY) license (http://creativecommons.org/licenses/by/4.0/). 